\title{
Biochemistry and molecular biology of galactoside transport and metabolism in lactic acid bacteria
}

\author{
B Poolman \\ Department of Microbiology, University of Groningen, Kerklaan 30 9NN 9751 Haren, \\ The Netherlands
}

\begin{abstract}
Summary - Until a few years ago the description of the pathways of transport and metabolism of galactosides in lactic acid bacteria was mainly phenomenological. Different transport and enzymatic activities had been detected but the individual components (proteins, enzymes) were largely unknown and the genes had not yet been isolated. In this paper I will address the different transport mechanisms and metabolic pathways of galactosides in lactic acid bacteria, and indicate the molecular level at which these studies have evolved. The genes encoding galactoside transport ATPases ion linked galactoside transporters and phosphoenolpyruvate:galactoside phosphotransferase systems (PTS) have been isolated and characterized from a number of lactic acid bacteria. In addition, the genes encoding subsequent steps of lactose (galactose) metabolism, ie those encoding the Leloir and Tagatose 6 phosphate pathway enzymes, have been characterized at a genetic and to some extent at a biochemical level. The genes encoding the transport proteins and metabolic enzymes are often clustered in a single operon or regulon which allows co-ordinate expression of the polypeptides. Transport of galactosides has most been thoroughly studied in Streptococcus thermophilus where the transport gene encodes a chimeric protein (LacS) that is composed of a carrier domain homologous to various ion linked carbohydrate transporters and a hydrophilic domain homologous to the IIA phosphoryl transfer protein of various PTSs. LacS has been extracted from membrane vesicles and functionally reconstituted into proteoliposomes, and the energetics and kinetic mechanism of transport have been analyzed. LacS mediates galactoside $\mathrm{H}^{+}$symport and galactoside exchange (eg lactose/galactose exchange) of which the latter reaction is highly favoured under physiological conditions. Details of the galactoside translocation pathway have been established by studying mutant LacS proteins in which the galactoside movement is uncoupled from the $\mathrm{H}^{+}$transport whereas the exchange reaction takes place normally. The data offer a rationale for the observed excretion of galactose by $\mathrm{Gal}^{-}$and $\mathrm{Gal}^{+}$strains of $S$ thermophilus under conditions of growth in the presence of excess lactose.
\end{abstract}

sugar transport ATPase / ion-linked transport / exchange / PTS / galactoside metabolism

Résumé - Biochimie et biologie moléculaire du transport et du métabolisme des galactosides chez les bactéries lactiques. II y a quelques années encore, la description des voies de transport et du métabolisme des galactosides chez les bactéries lactiques était principalement phénoménologique. Des systèmes de transport et des activités enzymatiques différentes avaient été détectés, mais leurs composants individuels (protéines, enzymes) étaient pour la plupart inconnus et 
les gènes n'avaient pas été isolés. Dans cet article, je parlerai des différents mécanismes de transport et des voies métaboliques des galactosides des bactéries lactiques, et j'indiquerai le niveau moléculaire auquel ces études ont abouti. Les gènes codant pour les ATPases du transport des galactosides, les transporteurs ions-dépendants et les systèmes phosphoénolpyruvate:galactoside phosphotransférase (PTS) de nombreuses bactéries lactiques ont été isolés et caractérisés. De plus, les gènes codant pour les étapes suivantes du métabolisme du lactose (galactose), c'est-à-dire ceux codant pour les enzymes des voies de Leloir et du tagatose-6-phosphate, ont été caractérisés au niveau génétique et, dans une certaine mesure, au niveau biochimique. Les gènes codant pour les protéines de transport et les enzymes du métabolisme sont souvent groupés en un opéron ou régulon unique, ce qui permet leur expression coordonnée. Le transport des galactosides a été étudié de manière approfondie chez Streptococcus thermophilus où les gènes de transport codent pour une protéine-chimère (LacS) constituée d'un domaine carrier homologue à des transporteurs de glucides ions-dépendants variés, et un domaine hydrophile homologue à la protéine phosphotransférase IIA de différents systèmes PTS. LacS a été extraite de vésicules membranaires et fonctionnellement reconstituée dans des protéoliposomes, et les mécanismes énergétiques et cinétiques du transport ont été analysés. LacS intervient dans le symport galactoside $\mathrm{H}^{+}$et dans l'échange des galactosides (c'est-à-dire l'échange lactose/galactose), ce demier étant hautement favorisé dans les conditions physiologiques. Les détails de la voie de translocation des galactosides ont été établis en étudiant les protéines mutantes LacS dans lesquelles le mouvement des galactosides est découplé du transport des ions $\mathrm{H}^{+}$alors que la réaction d'échange se déroule normalement. Les données offrent une explication pour l'excrétion de galactose observée dans les souches Gal' et Gal de S thermophilus dans des conditions de croissance en présence d'un excès de lactose.

\section{ATPase du transport des glucides / transport ions-dépendant / échange / PTS / métabolisme des galactosides}

\section{INTRODUCTION}

The initial event in the metabolism of monoand disaccharides involves the translocation of these molecules across the cytoplasmic membrane. The systems by which the carbohydrate molecules are transported can be subdivided into 3 classes that differ in their mechanism of energy coupling: i) in case of primary transport the translocation of a sugar is driven by the hydrolysis of an energy-rich chemical bond (eg ATP; fig 1); ii) for secondary transport the driving force for the translocation of a sugar molecule is supplied by the sugar concentration gradient, and, if another molecule is co- or counter transported with the carbohydrate, the (electro-) chemical gradient of this coupling molecule, ie accumulation is achieved by the downhill movement of another molecule (fig 2); iii) for group translocation transport the translocation of the sugar molecule across the cy- toplasmic membrane is coupled to the chemical modification of the molecule, ie transport concomitant with phosphorylation of the substrate by the PTS (fig 3 ). These different mechanisms of transport have been observed for a wide variety of sugars but only those that mediate lactose (galactoside) transport in lactic acid bacteria will be described.

Depending on the transport mechanism the following step in lactose metabolism involves hydrolysis of the free sugar by Bgalactosidase (LacZ), yielding glucose and galactose (fig 2), or hydrolysis of lactose 6phosphate by a phospho-ß-galactosidase (LacG), yielding glucose and galactose 6phosphate (fig 3). The 2 major pathways of glucose degradation in lactic acid bacteria are the glycolytic (or Embden-MeyerhofParnas) and the phosphoketolase pathways (Kandler, 1983). The glycolytic pathway is operative in Lactococcus spp, homofermentative lactobacilli (eg Lactoba- 
cillus delbrueckii subsp bulgaricus and helveticus), Pediococci and Streptococcus thermophilus, whereas the phosphoketolase pathway(s) resulting in heterofermentation is present in Leuconostoc spp, Lactobacillus buchneri, Lactobacillus brevis and Lactobacillus casei (Kandler, 1983). Galactose is metabolized further via the Leloir pathway (fig 2), whereas galactose 6-phosphate enters the tagatose 6phosphate pathway (fig 3).

\section{GALACTOSIDE TRANSPORT ATPASES}

Recently, a binding protein-dependent transport system facilitating the uptake of multiple sugars, ie the galactosides raffinose and melibiose, and isomaltotriose, has been described for Streptococcus mu-

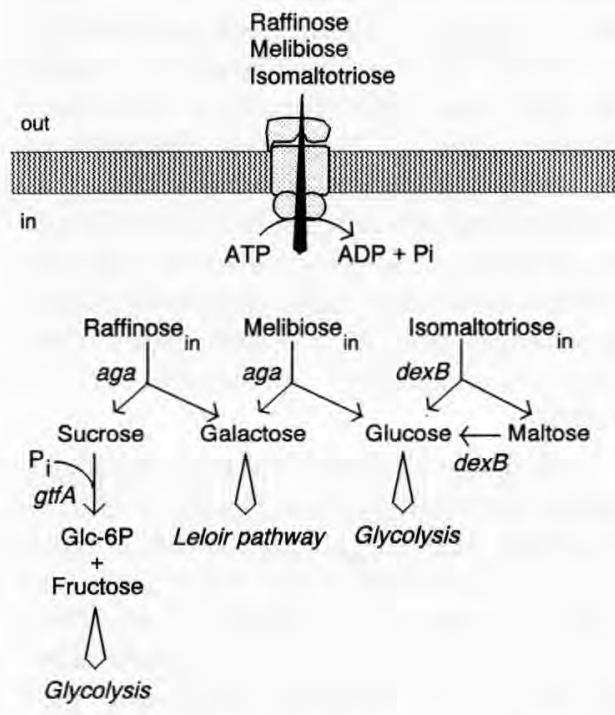

Fig 1. Sugar transport ATPase and multiple sugar metabolism. aga, $\alpha$-galactosidase; dexB, dextran glucosidase; gtfA, sucrose phosphorylase (for details, see Russell et al, 1992). tans (Russell et al, 1992) (fig 1). The system includes a sugar-binding lipoprotein (MsmE), 2 membrane proteins (MsmF, MsmG) and a protein (MsmK) containing the ATP-binding cassette (Hyde et al, 1990). The genes encoding these proteins are clustered together with genes encoding an $\alpha$-galactosidase (Aga), sucrose phosphorylase (GtfA), dextran glucosidase (DexB), and the Leloir pathway enzymes. Although the nature of the driving force of the Msm system has not been demonstrated biochemically, the sequence homology with other transport ATPases makes it likely that uptake is directly energized by ATP (Poolman et al, 1992a). Based on similarities in the primary structure of polypeptide (s) from Leuconostoc lactis, that surprising-

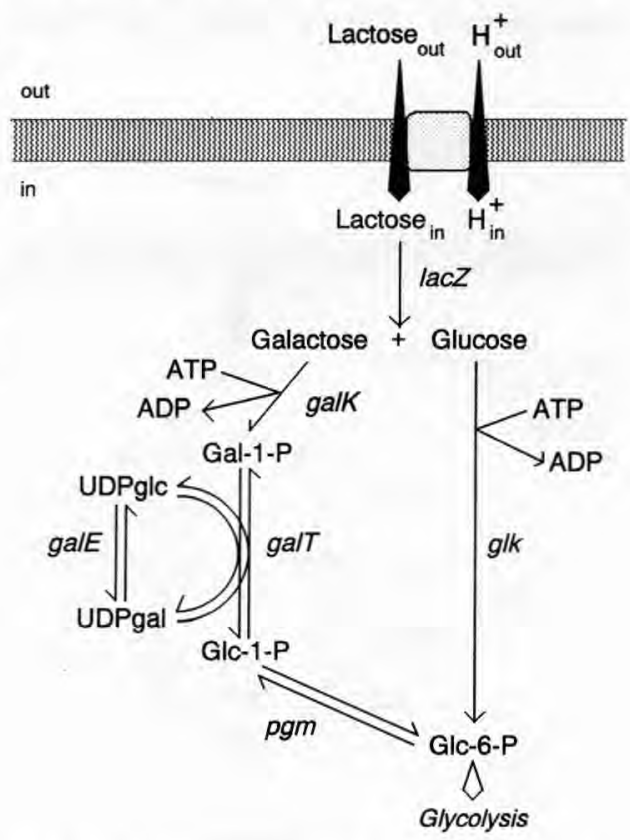

Fig 2. Galactoside- $\mathrm{H}^{+}$symport and Leloir pathway. lacZ, B-galactosidase; galK, galactokinase; galT, UDPglucose : galactose 1-phosphate uridylyl transferase; galE, UDPglucose 4-epimerase; pgm, phosphoglucomutase; glk, glucokinase. 
ly complement an Escherichia coli lacY mutation, and components of binding protein dependent transporters (David, 1992) it is tempting to speculate that a lactose transport ATPase is also present in this organism. The number of ATP molecules hydrolyzed per solute taken up by the transport ATPases is most likely 1-2 (Poolman et al, 1992a) which makes these transporters energetically expensive as compared to the ion-linked transporters, exchange systems and PTS (see below). Generally the binding protein dependent transporters bind their substrates with very high affinity which allows efficient transport in the nano- and submicromolar range of concentrations.

Downstream of the putative lactose transport ATPase genes of $L C$ lactis, 2 translationally coupled genes (lacL and

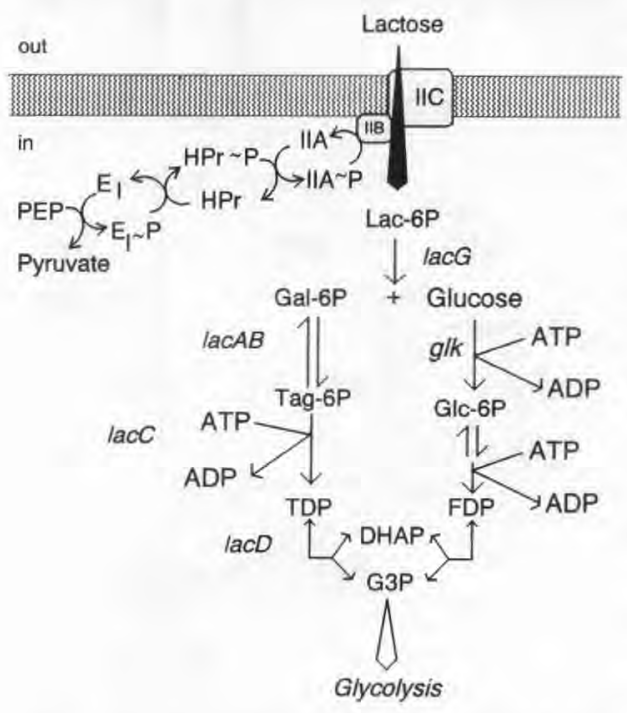

Fig 3. Lactose-PTS and tagatose 6-phosphate pathway. lacG, phospho-ß-galactosidase; lacAB, galactose 6-phosphate isomerase; lacC, tagatose 6-phosphate kinase; lacD, tagatose 1,6-diphosphate aldolase; glk, glucokinase.
IacM) have been found that encode a functional B-galactosidase (David et al, 1992). The deduced amino acid sequences of LacL and LacM are homologous to the amino- and carboxy-terminal parts, respectively, of the B-galactosidases (LacZ) of $S$ thermophilus, $L b$ bulgaricus and $E$ coli.

\section{ION-LINKED GALACTOSIDE TRANSPORTERS AND GALACTOSIDE EXCHANGE}

Ion-linked galactoside transport has first been described for the atypical $L$ lactis 7962 where methyl-B-D-galactopyranoside (TMG) accumulation has been shown to be coupled to the downhill movement of a proton (Kashket and Wilson, 1973). The system is highly specific for galactose, TMG and other galactose analogs, but exhibits poor affinity for lactose. A similar system has been described for $L c$ lactis ML3 (Thompson, 1980). Lactose transporters driven by the electrochemical proton gradient have been described for $S$ thermophilus and $L b$ bulgaricus (Poolman et al, 1989; unpublished results). These lactose transporters turn out to be specific not only for lactose ( $\beta$-galactoside) but also for melibiose ( $\alpha$-galactoside), galactose (monosaccharide) and to a lesser extent raffinose (trisaccharide) (Poolman et al, 1992b).

The genes encoding the lactose (galactoside) transport proteins (LacS) of $S$ thermophilus and $L b$ bulgaricus have been cloned, characterized and functionally expressed in E coli (Poolman et al, 1989, 1992b). Both proteins are composed of an amino-terminal polytopic membrane protein domain (carrier domain) and a carboxy-terminal hydrophilic domain. The carrier domain is homologous to the melibiose carrier protein (MelB) of $E$ coli, the xylose carrier protein (XyIP) of Lactobacillus pen- 
tosus, and some other carrier proteins that most likely couple the uphill movement of sugars to the downhill movement of a cation (proton, sodium or lithium). The hydrophilic domain of LacS is homologous to various IIA protein(s) or protein domains of PTS, previously indicated as enzyme III or enzyme III-like domain. The chimeric nature of LacS makes this transporter unique and suggests that it shares features of both ion-linked transporters and PTS.

Studies on the kinetic mechanism of LacS have indicated that a full translocation cycle involves stoichiometric transmembrane movement of galactosides and protons (fig 4). On the other hand, with saturating concentrations of galactosides (eg lactose and galactose) on either side of the membrane, release of substrate (and proton) is immediately followed by (re)binding of substrate (and proton) rather than by reorientation of the 'empty' binding site(s) (Foucaud and Poolman, 1992). Under these conditions the carrier protein performs an exchange reaction with no net proton translocation. Since $S$ thermophilus and $L b$ bulgaricus strains excrete galactose into the medium in amounts stoichiometric with the uptake of lactose, the suggestion has been made that under physiological conditions lactose is taken up in exchange for a galactose molecule (Poolman et al, 1989; Poolman, 1990). Evidence in favour of this notion has been obtained from kinetic studies of galactoside transport (Foucaud and Poolman, 1992) and comparison of in vivo transport and metabolism rates (Poolman and Foucaud, unpublished). The recent suggestion that the galactoside transporter of $S$ thermophilus is a strict lactose/galactose antiporter (Hutkins and Ponne, 1991) is not correct. Although the lactose/galactose exchange reaction may be favoured under many conditions, the exchange mode simply reflects partial steps, forward and backward reactions with no net proton translocation, of a complete translocation cycle involving sugar and proton uptake on one side and release on the other side of the membrane, and reorientation of loaded and unloaded substrate binding sites (Foucaud and Poolman, 1992; see below). Attempts are being made to refine the kinetic scheme for LacS facilitated transport by using mutants [LacS(H379D) and LacS(E379Q)] that are conditionally uncoupled in the galactoside$\mathrm{H}^{+}$symport reaction.

The exchange reaction has advantages over galactoside- $\mathrm{H}^{+}$symport for the uptake of lactose and excretion of galactose. First, although uptake of lactose is stimulated by the transmembrane electrochemical proton gradient $(\Delta p)$, efflux is inhibited and net exit will only occur if the galactose concentration gradient $\left(\Delta_{\mu g a l} / F\right)$ exceeds the $\Delta p$.

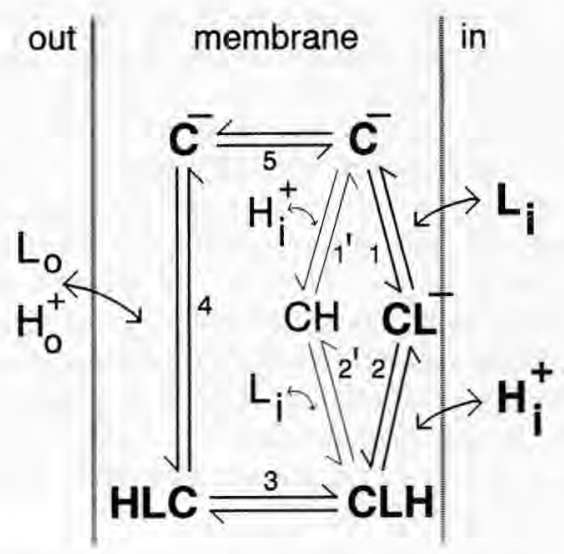

Fig 4. Kinetic scheme for LacS- mediated galactoside- $\mathrm{H}^{+}$symport and galactoside exchange. $\mathrm{C}$, carrier protein; L, ligand (galactoside); $\mathrm{H}^{+}$, proton. In the model ordered binding and release of substrate and proton (substrate first, proton last (bold type letters), and proton first, galactoside last) on the inner surface of the membrane are indicated. The order of binding and release on the outer surface of the membrane are not specified. The negative charge carried by the unloaded carried and binary carried-ligand complex is indicated (for details, see Foucaud and Poolman, 1992). 
Instead the linkage of lactose uptake to galactose excretion via an exchange reaction assures tight coupling to the metabolism, which minimizes (excessive) galactose accumulation and possible product inhibition (Poolman, 1990). Second, efflux is significantly rate-limited by the release of the proton at the outer surface of the membrane, and, as a consequence, extremely slow below $\mathrm{pH} 7$; similarly, influx is inhibited by a low intracellular $\mathrm{pH}$ whereas exchange is less drastically affected by the absolute $\mathrm{H}^{+}$concentrations (Foucaud and Poolman, 1992). In fact, exchange proceeds maximally between $\mathrm{pH} \mathrm{6-7}$ and with rates at least one order of magnitude faster than the corresponding galactoside- $\mathrm{H}^{+}$ symport.

Carboxy-terminal deletion mutants of LacS have been constructed which lack part or the entire IIA domain (approximately 170 amino acids) (Poolman and Nieuwenhuis, unpublished observations). Studies with $\operatorname{LacS}(\Delta 166)$ and other mutants indicate that the basic properties of transport are retained in these mutants. In the presence of PEP, and purified enzyme I and $\mathrm{HPr}$, the general phosphoryl transfer proteins of the PTS, the IIA domain of LacS can be phosphorylated at a specific histidine residue (His-552) (Poolman et al, $1992 b)$. Currently, the kinetic mechanism of 'phosphorylated' LacS is compared with that of the unphosphorylated protein both in vitro and in vivo.

Galactoside (TMG) transport has also been studied in the heterofermentative lactobacilli $L b$ brevis and $L b$ buchneri (Romano et al, 1987). In the presence of arginine as exogenous energy source TMG is accumulated by these cells most likely via a galactoside- $\mathrm{H}^{+}$symport mechanism. Addition of glucose results in a rapid efflux of TMG, and it has been suggested that glucose converts the ion-linked transporter into an uniport mechanism (Romano et al, 1987). Since addition of glucose also elic- its the phosphorylation of the energy coupling proteins of the PTS, it is conceivable that phosphorylation of a domain similar to IIA in LacS mediates the apparent conversion in transport mechanism.

The lactose transport genes (lacS) of $S$ thermophilus and Lb bulgaricus are organized in an operon that also contains the B-galactosidase gene (lacZ) (Poolman et al, 1989; Schmidt et al, 1989). Downstream of the lac operon of $L b$ bulgaricus, an open reading frame (ORF) has been found that shows similarity to various repressor proteins, including Lacl, GalR, and PurR (Yoast et al, 1990). It has been suggested that this ORF does not encode a functional repressor protein which would explain the constitutive expression of the lac genes in Lb bulgaricus. In contrast, expression of the lac genes in $S$ thermophilus is inducible but the regulatory protein(s) have not yet been identified. Induction of the lac (and gal) genes is effected by galactose and galactose analogs, but not by lactose, whereas glucose represses (Poolman et al, 1990; Foucaud and Poolman, unpublished observations). Sequences strongly resembling those of cataboliterepressed genes of Gram-positive bacteria have been detected in the lac promoter region of $S$ thermophilus, suggesting that expression of the lac genes is also under glucose (catabolite) repression control.

\section{PEP:GALACTOSIDE PHOSPHOTRANS- FERASE SYSTEMS (PTS)}

The genes encoding IIBC (or lactose specific enzyme II) and IIA (previously, factor IIILac or enzyme III-lac) components of the lactose PTS as well as the phospho- $\beta$ galactosidase of $L$ lactis and $L b$ casei have been cloned and sequenced (Boizet et al, 1988; Porter and Chassy, 1988; Alpert and Chassy, 1988, 1990; de Vos et al, 1990). 
The genes are contained in an operon structure which has best been studied for $L$ lactis. The lactose operon of $L$ lactis also comprises the tagatose 6-phosphate pathway genes (van Rooyen et al, 1991; see below). The expression of the lac genes of $L$ lactis and $L b$ casei is induced during growth on lactose and galactose. A repressor protein (LacR) acting at the level of transcription mediates the expression of the lac genes in L lactis (van Rooyen et al, 1991; 1992); tagatose 6-phosphate most likely functions as the effector molecule (inducer). LacR belongs to the family of DNAbinding proteins that includes the $E$ coli repressors DeoR, FucR and GutR, and LacR of Staphylococcus aureus.

Sugar transport mediated by the PTS involves phosphoryl transfer from PEP via the general cytoplasmic components enzyme I and HPr to the sugar specific component(s) IIABC. The phosphoenzyme intermediates of enzyme I, HPr and IIA of all PTS studied to date carry the phosphoryl group on a histidine residue (see Pas and Robillard, 1988). In addition to the histidine, HPr in Gram-positive bacteria carries a specific serine residue that is phosphorylated by an ATP dependent protein kinase (Reizer et al, 1985). This phosphorylation site does not play a role in the phosphoryl transfer per se but modulates the PTS activity. Biochemically it has been demonstrated that phosphorylation of IIB-mannitol of $E$ coli is at a specific cysteine residue (Pas and Robillard, 1988). This phosphorylation site actually transfers the phosphoryl group to the sugar that is translocated by IIC. By replacing each of the histidine and cysteine residues of IIBC of the lactose PTS of $L b$ casei evidence has been obtained that also a single cysteine (Cys384) mediates the final phosphoryl transfer to lactose (Alpert and Chassy, 1990).

In addition to catalyzing galactoside uptake concomitant with phosphorylation of the sugar, IIBC of the lactose PTS is also believed to catalyze efflux (expulsion) of intracellularly formed free galactosides (Reizer et al, 1985; Thompson, 1987). This expulsion of galactosides is phenomenologically similar to that observed in the heterofermentative lactobacilli where a secondary transport mechanism has been implicated in the efflux of free galactosides (see above, ion-linked galactoside transporters and galactoside exchange). For details on galactoside efflux in lactic acid (and other Gram-positive) bacteria the reader is referred to Reizer (1989).

\section{LELOIR PATHWAY}

The enzymes of the Leloir pathway of galactose metabolism include galactokinase (GalK) which phosphorylates galactose at the C-1 position, UDPglucose:galactose-1phosphate uridylyltransferase (GalT) which transfers the UDP group from UDPglucose to galactose-1-phosphate, UDPglucose 4epimerase (GalE) which catalyzes the epimerization of UDPgalactose to UDPglucose (fig 2). UDPglucose synthetase (GalU, not shown) and phosphoglucomutase (Pgm) are also needed for galactose metabolism but the corresponding genes do not form part of the gal operon. In E coli these enzymes are synthesized constitutively (Adhya, 1987). The reversible reactions of the Leloir pathway allow cells to make UDPgalactose in the absence of exogenous galactose which can be used for the synthesis of complex (extracellular) polysaccharides.

The genes encoding GalT and GalE of $S$ thermophilus (Poolman et al, 1990; unpublished observations), and GalK and GalT of Lactobacillus helveticus (Mollet and Pilloud, 1991) have been isolated and characterized. The primary structures of GalE from $S$ thermophilus, and GalK from $\mathrm{Lb}$ helveticus show significant similarity to 
the corresponding polypeptides of other pro- and eukaryotic organisms. The deduced amino acid sequences of GalT from $L b$ helveticus and $S$ thermophilus indicate that, so far, this enzyme is unique for lactic acid bacteria (Mollet and Pilloud, 1991; Poolman, unpublished observations). Interestingly, a gene encoding an aldose 1-epimerase (mutarotase) (GalM) is associated with the gal and lac gene cluster of $S$ thermophilus and $L b$ helveticus. GalM catalyzes the anomeric interconversion of D-glucose and other aldoses, a process (mutarotation) that also occurs spontaneously (Poolman et al, 1990). The role of GalM in galactoside metabolism in the lactic acid bacteria is unclear, but its presence suggests that one or more steps in the carbohydrate metabolism requires either an $\alpha$ - or $\beta$-sugar anomer.

The majority of 'wild type' strains of $S$ thermophilus (and $L b$ bulgaricus) cannot metabolize galactose, and in case of $S$ thermophilus the Gat phenotype has been attributed to a defect in the induction mechanism for galactokinase (Thomas and Crow, 1984; Hutkins et al, 1985). Under the selective pressure of the chemostat Gal ${ }^{+}$variants of $S$ thermophilus could be isolated indicating that ga/K is present in the organisms (Thomas and Crow, 1984). The level of galactokinase was many times greater in the $\mathrm{Gal}^{+}$variant than in the parent strain. By contrast we have been unable to detect activity of any of the Gal enzymes in $L b$ bulgaricus (strains B131 and B032; Poolman, unpublished observations). Moreover, the region upstream of the lac operon of $\angle b$ bulgaricus B131 does not code for any of the Gal enzymes as does the corresponding region in $S$ thermophilus. This suggests that these $L b$ bulgaricus strains are not only phenotypically but also genotypically $\mathrm{Gal}$ negative.

In the section on ion-linked galactoside transporters and galactoside exchange it has been indicated that the lactose/ galactose exchange reaction is favoured over lactose uptake and galactose excretion via separate steps. Since GalK+ strains of $S$ thermophilus selected in lactose-limited chemostats are very unstable and lose their ability to utilize galactose rapidly upon transfer to media containing an excess of lactose (Thomas and Crow, 1984), it has been suggested that the $\mathrm{Gal}^{-}$ phenotype of most strains may be a favourable trait due to the more rapid uptake (and metabolism) of lactose in the absence of galactokinase (Poolman, 1990). Only when lactose becomes limiting, which will not easily happen in the 'milk environment', the organism may switch to the $\mathrm{Gal}^{+}$phenotype.

\section{TAGATOSE 6-PHOSPHATE PATHWAY}

In the tagatose 6-phosphate pathway galactose 6-phosphate, obtained from the hydrolysis of lactose 6-phosphate or the coupled transport and phosphorylation of galactose mediated by PTS (Thompson, 1980), is isomerized to tagatose 6phosphate by galactose 6-phosphate isomerase (LacAB) (fig 3). Subsequently, galactose 6-phosphate is phosphorylated at the expense of ATP by tagatose 6phosphate kinase (LacC), whereafter the tagatose 1,6-diphosphate is cleaved to dihydroxyaceton phosphate and glyceraldehyde 3-phosphate by an aldolase (LacD) (fig 3 ).

The genes encoding $L a C A B, L a c C$ and LacD have been isolated and characterized genetically (van Rooyen et al, 1991). and they form part of the operon that also contains the lactose specific components of the PTS (LacE and LacF) and phospho$B$-galactosidase (LacG) in $L$ lactis (de Vos et $a l, 1990)$. Expression of both lacA and $\operatorname{lac} B$ is required for galactose 6 -phosphate 
isomerase activity suggesting a multimeric state of the enzyme. The tagatose 1,6diphosphate aldolase enzyme of $L$ lactis has been purified and characterized biochemically (Crow and Thomas, 1982).

\section{ACKNOWLEDGMENT}

The author's research has been made possible by a fellowship from the Royal Netherlands Academy of Arts and Sciences.

\section{REFERENCES}

Adhya S (1987) The galactose operon. In: Escherichia coli and Salmonella typhimurium: Cellular and Molecular Biology (Neidhardt FC, ed) Am Soc Microbiol, Washington, DC

Alpert CA, Chassy BM (1988) Molecular cloning and nucleotide sequence of the factor IIILac gene of Lactobacillus casei. Gene 62, 277 288

Alpert CA, Chassy BM (1990) Molecular cloning and DNA sequence of lacE, the gene encoding the lactose-specific enzyme II of the phosphotransferase system of Lactobacillus casei. J Biol Chem 265, 22561-22568

Boizet B, Villeval D, Slos P, Novel M, Novel G, Mercenier A (1988) Isolation and structural analysis of the phospho- $\beta$-galactosidase gene from Streptococcus lactis Z268. Gene $62,249-261$

Crow VL, Thomas TD (1982) D-Tagatose 1,6diphosphate aldolase from lactic streptococci: purification, properties, and use in measuring intracellular tagatose 1,6-diphosphate. $J$ Bacteriol 151, 600-608

David S (1992) Genetics of mesophilic citrate fermenting lactic acid bacteria. PhD thesis, Agric Univ Wageningen, The Netherlands

David S, Stevens H, van Riel M, Simons G, de Vos WM (1992) Leuconostoc lactis Bgalactosidase is encoded by two overlapping genes. J Bacteriol 174, 4475-4481

De Vos WM, Boerrigter I, van Rooijen RJ, Reiche B, Hengstenberg W (1990) Characterization of the lactose-specific enzymes of the phosphotransferase system in Lactococcus lactis. J Biol Chem 265, 22554-22560

Foucaud C, Poolman B (1992) Lactose transport system of Streptococcus thermophilus: reconstitution of the protein and characterization of the kinetic mechanism of transport. $J$ Biol Chem 267, 22087-22094

Hutkins RW, Ponne C (1991) Lactose uptake driven by galactose efflux in Streptococcus thermophilus: evidence for a galactoselactose antiporter. Appl Environ Microbiol 57. 941-944

Hutkins R, Morris HA, McKay LL (1985) Galactokinase activity in Streptococcus thermophilus. Appl Environ Microbiol 50, 777-780

Hyde SC, Emsley P, Hartshorn MJ, Mimmack MM, Gileadi U, Pearce SR, Gallagher MP, Gill DR, Hubbard RE, Hubbard RK, Higgins CF (1990) Structural model of ATP-binding protein associated with cystic fibrosis, multidrug resistance and bacterial transport. $\mathrm{Na}$ ture $346,362-365$

Kandler O (1983) Carbohydrate metabolism in lactic acid bacteria. Antonie van Leeuwenhoek 49, 209-224

Kashket ER, Wilson TH (1973) Proton-coupled accumulation of galactoside in Streptococcus lactis 7962. Proc Natl Acad Sci USA 70, 2866-2869

Mollet B, Pilloud N (1991) Galactose utilization in Lactobacillus helveticus : isolation and characterization of the galactokinase (gaK) and galactose-1-phosphate uridyl transferase ( $g a / T$ ) genes. J Bacteriol 173, 4464-4473

Pas HH, Robillard GT (1988) S-Phosphocysteine and phosphohistidine are intermediates in the phosphoenolpyruvate-dependent mannitol transport catalyzed by Escherichia coli ElIMtt. Biochemistry 27, 5835-5839

Poolman B (1990) Precursor/product antiport in bacteria. Mol Microbiol 4,1629-1636

Poolman B, Royer TJ, Mainzer SE, Schmidt BF (1989) Lactose transport system of Streptococcus thermophilus: a hybrid protein with homology to the melibiose carrier and enzyme III of phosphoenol-pyruvate-dependent phosphotransferase systems. J Bacteriol 171, 244-253

Poolman B, Royer TJ, Mainzer SE, Schmidt BF (1990) Carbohydrate utilization in Streptococcus thermophilus: characterization of the 
genes for aldose 1-epimerase (mutarotase) and UDPglucose 4-epimerase. J Bacteriol 172, 4037-4047

Poolman B, Molenaar D, Konings WN (1992a) Diversity of transport mechanisms in bacteria. In: Handbook of Biomembranes (Shinitzky M,ed) Balaban Publ Rehovot, Israel, vol 2

Poolman B, Modderman R, Reizer J (1992b) Lactose transport sytem of Streptococcus thermophilus: the role of histidine residues. $J$ Biol Chem 267, 9150-9157

Porter EV, Chassy BM (1988) Nucleotide sequence of the B-D-phosphogalactoside galactohydrolase gene of Lactobacillus casei : comparison to analogues $p b g$ genes of other Gram-positive organisms. Gene 62, 263-276

Reizer J (1989) Regulation of sugar uptake and efflux in Gram-positive bacteria. FEMS Microbiol Rev 63, 149-156

Reizer J, Deutscher J, Sutrina S, Thompson J, Saier MH (1985) Sugar accumulation in Gram-positive bacteria: exclusion and expulsion mechanisms. Trends Biochem Sci 10, 32-35

Romano AH, Brino G, Peterkofsky A, Reizer J (1987) Regulation of $\beta$-galactoside transport and accumulation in heterofermentative lactic acid bacteria. J Bacteriol 169, 5589-5596

Russell RRB, Aduse-Opoku J, Sutcliffe IC, Tao L, Ferretti JJ (1992) A binding proteindependent transport system in Streptococcus mutans responsible for multiple sugar metabolism. J Biol Chem 267, 4631-4637
Schmidt BF, Adams LM, Requadt C, Power S, Mainzer SE (1989) Expression and nucleotide sequence of the Lactobacillus bulgaricus B-galactosidase gene cloned in Escherichia coli. J Bacteriol 171, 625-635

Thomas TD, Crow VL (1984) Selection of galactose-fermenting Streptococcus thermophilus in lactose-limited chemostat cultures. Appl Environ Microbiol 48, 186-191

Thompson J (1980) Galactose transport systems in Streptococcus lactis. J Bacteriol 144, 683-691

Thompson J (1987) Sugar transport in the lactic acid bacteria. In : Sugar Transport and Metabolism in Gram-Positive Bacteria (Reizer J, Peterkofsky A, eds) Ellis Horwood Ltd, Chichester, UK

Van Rooijen RJ, Schalkwijk S, de Vos WM (1991) Molecular cloning, characterization, and nucleotide sequence of the tagatose 6phosphate pathway gene cluster of the lactose operon of Lactococcus lactis. J Biol Chem 266, 7176-7181

Van Rooijen RJ, Gasson MJ, de Vos WM (1992) Characterization of the Lactococcus lactis lactose operon promoter: contribution of flanking sequences and LacR repressor to promoter activity. J Bacteriol 174, 2273-2280

Yoast S, Schmidt BF, Royer TJ, Poolman B (1990) Characterization of the $3^{\prime}$ end of the lactose operon from Lactobacillus delbrueckii subsp bulgaricus. FEMS Microbiol Rev 87 , 18 